Thorax (1954), 9, 10.

\title{
THE PRODUCTION OF PLEURAL ADHESIONS BY KAOLIN INJECTION
}

\author{
BY \\ JAMES MAXWELL \\ From the Royal Chest Hospital, London
}

(RECEIVED FOR PUBLICATION SEPTEMBER 3, 1953)

The treatment of spontaneous pneumothorax has received considerable attention in the literature during the past 20 years. It is accepted that the great majority of cases are due to the rupture of a subpleural cyst or bulla ; in a small minority there may be an acquired organic lesion of the underlying lung, such as tuberculosis, lung abscess, bronchiectasis, cystic disease, or some form of growth. This group is commonly excluded from discussions on treatment because the management of the pneumothorax is closely linked with the management of the underlying condition, and it will not be further discussed in this paper.

The management of the larger, "simple" group runs along well-defined lines. It is not customary to take action on the occasion of the first attack, for the air absorbs spontaneously as a rule and the patient appears to make a complete recovery. If, however, there should be one or more recurrences it is usual to undertake some form of pleurodesis, or even a surgical operation, in order to remove or obliterate the cystic area in the lung. This attitude towards the management of the initial spontaneous pneumothorax is conditioned by the view that recurrence is less likely than not. Movitt, Smith, and Eloesser (1947) quote various authors whose figures for recurrences vary between 20 and $45 \%$, but this statement is really meaningless, for no allowance is made for the varying periods of time during which the patients were kept under observation. If one takes a series of cases of known spontaneous pneumothorax it is only possible to state that, in so many, there had been more than one attack, but these figures refer only to a limited period in the life history of the patient and they are certain to need revision in an upward direction as the years go by. The figures already published therefore represent a minimum, and it is probably correct to state, contrary to the accepted belief, that recurrence is more likely than not; in other words, that the pneumothorax will probably recur in more than half of a group of cases. In fact, it appears to be logical to state that any spontaneous pneumothorax is potentially recurrent, and to draw the conclusion that it is advisable to adopt treatment on the occasion of the first recognized attack.

Artificial fusion of the pleura dates back to 1901, when Spengler (1906) reported on the effect of injections of a hypertonic solution of glucose. His results could not have been very satisfactory because, in 1906, he appears to have been the first to advocate the use of $0.5 \%$ solution of silver nitrate. For many years after this there was no report of progress in the treatment of spontaneous pneumothorax although a certain amount of work must have been carried on in the meantime.

Bethune (1935) advocated poudrage of the pleura with iodized talc, and Chandler (1939) described the results of the injection of a solution of oil of gomenol in olive oil. In the same year Hennell and Steinberg (1939) advocated the use of iodized oil or glucose solution. After the war there was a revival of interest in the condition and a number of papers have been published within the past few years. Steele (1947) reviewed the results of the application of talc to the pleura. He concluded that the insufflation of talc powder was more effective than injection of a suspension of $N$ this material. Hetherington and Spencer (1947) reported good results from the use of oil of gomenol and oil of cajuput, but they stated that $\omega$ the injections were apt to cause "moderately severe" pain, for which morphia might be 0 required. Movitt and others (1947) discussed the $\mathbb{D}$ value of a number of substances, including blood, $\stackrel{\oplus}{?}$ guaiacol, iodoform, and lipiodol, but the variety of $T$ materials investigated appears to suggest that none $\stackrel{\circ}{\stackrel{D}{\mathbb{D}}}$ was entirely satisfactory. Brock (1948) elaborated the use of silver nitrate solution and advocated $\stackrel{\unrhd}{\unrhd}$ local excision if gross cystic disease were found to be present. Curti and Poulsen (1950) considered 
that " resection of the affected area " was the treatment of choice in younger patients and that silver nitrate should be reserved for debilitated elderly individuals.

Consideration of the numerous substances employed shows that they fall into two groups. In the first place there are those which act by chemical irritation of the pleura. The milder irritants, such as blood, glucose, and the essential oils, do not cause any gross loss of substance in the pleura and, in effect, they produce a mild aseptic pleurisy. Silver nitrate acts as a caustic on the pleura and causes actual destruction of tissue. The injection is accompanied by symptoms of shock, with severe pain in the chest, and it is by far the most drastic, as well as the most effective, of the chemical irritants used for producing pleural adhesion.

In the second group are substances which act by physical rather than by chemical means; hitherto the only example has been talc, which is a silicate of magnesia. This substance has not been uniformly successful and, in order to achieve the best results, it has been found necessary to use insufflations of the powder. In this connexion attention must be drawn to a recent paper by Baar (1953), who describes the formation of granulomatous masses after the use of talc in abdominal surgery. Ross and Fullerton are quoted by Waring (1944) as stating that talc causes formidable foreign body reactions in the pleura, which often thickens to the extent of $1 \mathrm{~cm}$. It would appear that some patients must be unduly susceptible to contact with talc, and very small quantities may produce considerable lesions. Although not much is known about the subject at present it would appear that talc is not a suitable substance to use as a routine. Nothing has so far been written about any similar action of kaolin, which is a silicate of aluminium.

The object of the present paper is to draw attention to the value of kaolin in producing a mechanical pleurisy with firm adhesions. The kaolin suspension is injected into the pneumothorax space and it is considered that the minute crystals act as an abrasive upon the endothelial lining of the pleura. There is no chemical action, so far as we know, and therefore there is no possibility of injury being caused to the tissues.

Although kaolin does not seem to have been used for the purpose of producing pleural adhesions in this country or in the United States it has been employed on the Continent, and particularly in Switzerland, for the past 10 years.
Details were published by Egger and Good (1945), in which they advocated the use of a single dose of $0.3 \mathrm{~g}$. of kaolin suspended in 1 or 2 ml. water. They claim that firm adhesions were produced in 10 to 14 days. In the present series the production of adhesions took considerably longer.

\section{TeChNiQue}

Various concentrations of suspension were employed in the first few cases. At first a $50 \%$ suspension was tried and it was found that, although the resulting liquid was of the consistency of thin mud, the material was perfectly easy to inject. Weaker suspensions were then used, and, in the bulk of cases in this series, a $25 \%$ suspension was found to be satisfactory. It is possible, of course, that an even more dilute suspension would be equally effective, but the lower limit of concentration necessary to produce the required pleural reaction has not yet been explored.

The technique of preparing the material is very simple, for $25 \mathrm{~g}$. of kaolin is suspended in distilled water and the volume is made up to $100 \mathrm{ml}$. The suspension is then filled into ampoules and sealed. In each case the ampoule is sterilized in the autoclave before use. The suspension has proved to be clean and easy to handle.

As a rule it has been found advisable to carry out the injection when the lung is about two-thirds expanded. In most cases it was found to be satisfactory to keep the patient in bed and to allow the lung to expand in the natural course of events. In some, where there was an unusually large quantity of air in the pleura, it was found necessary to remove quantities of air before the injection was carried out.

In each case in this series the volume of suspension injected into the pleura was $2 \mathrm{ml}$. The concentration was either $50 \%$ (five cases) or $25 \%$ (18 cases).

In every case pain developed on the affected side of the chest, but this was never very severe, and it responded easily to the simpler anodynes. Morphia was never found to be necessary. During the second day the temperature began to rise in all cases, reaching the maximum of $101^{\circ}$ on the third day after the injection. The duration of fever varied from four to eight days.

Evidence of pleurisy was afforded by the development of a considerable effusion in all cases. Physical signs were apparent by the fourth day and the fluid accumulated rapidly, reaching a maximum on the eighth day. In many of the cases no further action was taken, and the fluid and air both absorbed rapidly. As judged by fluoroscopic examination the pleura was everywhere in apposition during the third or fourth week. In a few cases fluid was removed, but this was never because the quantity was so great as to cause respiratory embarrassment. The reason for withdrawal of fluid in five cases was in order to carry out chemical analysis in an attempt to discover the fate of the kaolin. 
During 1951 pleurodesis was carried out in 12 cases and, during 1952, in 11 cases. In none of these has there been any recurrence of the pneumothorax of the treated side. In one case a pneumothorax occurred on the opposite side in 1953 (Case 2).

The clinical features of spontaneous pneumothorax do not need special description, but two of the cases considered in the present series deserve to be recorded because they illustrate the hazards to which patients with a weak spot in the pleura may be unwittingly subjected.

\section{CASE REPORTS}

CASE 1.-Mrs. A.E.G., aged 29, is a married woman who lives in India. In March, 1948, she experienced a right spontaneous pneumothorax which was only of moderate severity. The lung expanded completely in the course of a few weeks with conservative treatment. It was noticed at the time that there was an air-cyst, presumably a tension cyst, in the left lower lobe. On August, 1951, she travelled by air from Bombay to London. After leaving Rome she became suddenly and progressively short of breath and by the time the plane reached London Airport she was experiencing a marked degree of dypsnoea.

She was admitted to a nursing home and the radiographs showed an almost complete spontaneous pneumothorax on the right side. The air-cyst in the left lower lobe was very much larger than it had been three years before, and there appeared to be a very considerable reduction in the total ventilating space.

The patient recovered quite rapidly with rest, and it was decided that pleurodesis should be carried out. This was done by injecting intrapleurally $2 \mathrm{ml}$. of a $50 \%$ suspension of kaolin, and a satisfactory reaction was attained. On the eighth day after the operation $10 \mathrm{oz}$. of clear fluid was removed from the right pleural space. The lung expanded and all evidence of the pneumothorax had disappeared within three weeks. The patient returned to India and it appears that she has not so far experienced any further pleural incident, although she has since undergone general anaesthesia for the removal of the appendix.

This case serves to illustrate that there is a possible risk of the development of a spontaneous pneumothorax during air travel. It is reasonable to suppose that if the pleura had been fused at the time of the initial attack the patient would have been spared an alarming experience.

CASE 2.-Mr. S.B., aged 23, was seen in consultation on September 19, 1951. He had been in perfect health until September 15, 1951, when he experienced a sudden acute abdominal pain while on holiday. The abdominal picture was so pronounced that a provisional diagnosis of perforated duodenal ulcer was made, but the development of respiratory symp- toms led to a revision of the diagnosis. When the patient was first seen there were signs of a complete spontaneous pneumothorax on the left side, and pleural synthesis by means of kaolin was carried out a few days later. Recovery was uneventful.

The patient was seen again on December 22, 1952, when he himself recognized the development of a small spontaneous pneumothorax on the right side. In view of the fact that there were no symptoms and that the patient wished to spend Christmas at home, it was decided not to take action on this occasion. but to await further developments. The patient appeared again on March 5, 1953. Again he felt that a pneumothorax had occurred two days previously although he was not complaining of any particular symptoms.

It was somewhat surprising to note, in view of the comparative absence of symptoms, that the right lung was completely deflated. During the next two days he developed increasing dyspnoea and it became necessary to remove considerable quantities of air from the pleural space on three occasions. The puncture must have sealed about this time because the lung began to expand and the intrapleural pressures became negative. Kaolin was therefore injected into the pneumothorax space and again a satisfactory reaction was attained.

This case illustrates bilateral spontaneous pneumothorax with recurrence on the right side. It would, perhaps, have been advisable to carry out pleurodesis on the right side on the occasion of the first incident in December, 1952.

It seemed advisable to discover so far as possible what had happened to the kaolin which had been injected into the pleura. Fluid was therefore removed on the eighth day in five cases and analysed. Each sample was evaporated to dryness and the solid residue was ignited to destroy the organic matter. The residue was weighed after sulphation. The results of the analyses are shown in the table.

\begin{tabular}{|c|c|c|c|c|c|}
\hline \multirow{2}{*}{$\begin{array}{l}\text { Case } \\
\text { No. }\end{array}$} & \multicolumn{2}{|c|}{$\begin{array}{l}\text { Aluminium } \\
\left(\mathrm{As} \mathrm{Al}_{2} \mathrm{O}_{3}\right)\end{array}$} & \multicolumn{2}{|c|}{$\begin{array}{c}\text { Silica } \\
\left(\mathrm{As} \mathrm{SiO}_{2}\right)\end{array}$} & \multirow{2}{*}{$\underset{\mathrm{Al}_{2} \mathrm{O}_{3}: \mathrm{SiO}}{\text { Ratio }}$} \\
\hline & $\begin{array}{c}\% \\
\text { Calculated } \\
\text { on Residue }\end{array}$ & $\begin{array}{c}\% \\
\text { Calculated } \\
\text { on Fluid }\end{array}$ & $\mid \begin{array}{c}\% \\
\text { Calculated } \\
\text { on Residue }\end{array}$ & $\begin{array}{c}\% \\
\text { Calculated } \\
\text { on Fluid }\end{array}$ & \\
\hline $\begin{array}{l}1 \\
2 \\
3 \\
4 \\
5\end{array}$ & $\begin{array}{l}1 \cdot 1 \\
0 \cdot 24 \\
008 \\
0 \cdot 478 \\
0 \cdot 183\end{array}$ & $\begin{array}{l}0.0107 \\
0.002 \\
0.00079 \\
0.0050 \\
0.0019\end{array}$ & $\begin{array}{l}0.84 \\
7.11 \\
1.09 \\
0.495 \\
0.497\end{array}$ & 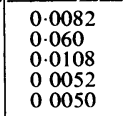 & $\begin{array}{l}1: 1 \cdot 19 \\
1: 30 \\
1: 14 \\
1: 1 \cdot 03 \\
1: 2 \cdot 72\end{array}$ \\
\hline
\end{tabular}

The ratio of aluminium to silica in kaolin is approximately $1: 1.2$. It will be seen that in Cases 1,4 , and 5 this ratio was approximately preserved. In Cases 2 and 3 it was unexpectedly found that the ratio was very much altered, and there was a comparative absence of aluminium in the fluid. 
It would appear that in these two cases the kaolin had been split into its component parts and that the aluminium fraction had been to a large extent absorbed from the fluid. The reason for this chemical change is not understood and further analysis is being undertaken in order to discover whether it happens in a significant proportion of cases and, if so, why it should occur.

\section{SUMMARY}

A kaolin suspension has been employed to cause pleural adhesion in 23 cases of spontaneous pneumothorax. The suspension is easy to handle and the resulting reactions are of moderate intensity. Only one injection has been found necessary in each case and, up to the time of writing, there has not been any recurrence. This method presents distinct advantages in comparison with silver nitrate solution.

It is a pleasure to express my thanks to $\mathrm{Mr}$. $\mathrm{H}$. Surfleet, M.P.S., of Kaylene Ltd., who kindly provided the suspensions of kaolin which were used and who was responsible for the chemical analyses of the samples of pleural fluid.

\section{REFERENCES}

Baar, F. (1953) Brit, med. J., 1, 1146

Bethune, N. (1935). J. thorac. Surg., 4, 251.

Brock, R. C. (1948). Thorax, 3, 88.

Chandler, V. G. (1939). Lancet, $2,638$.

Curti, P. C., and Poulsen, T. (1950). J. thorac. Surg., 19, 145.

Egger, K. von, and Good, H. (1945). Schweiz. Z. Tuberk., $2,24$.

Hennell, H., and Steinberg, M. F. (1939). Arch. intern. Med., 63, 648.

Hetherington, L. H. and Spencer, G. E. (1947). Dis. Chest, 13, 652. Movitt, E. R. Smith, J. V., and Eloesser, L. (1947). Ibid., 13, 221

Movitt, E. R., Smith, Beitr., klin. Chir., 49, 80.

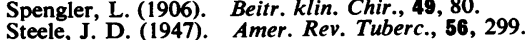

Waring, J. J. (1944). Spontaneous Pneumothorax. National Research Council, Office of Medical Information, Washington, D.C. 